\title{
THE DEVELOPING OF TEMATIK TEACHING MEDIA MAGIC PUZZLE THEME OF "BERBAGI PEKERJAAN" IN FOURTH GRADE OF PRIMARY SCHOOL
}

\author{
Dewi Saraswati \& Arfilia Wijayanti \\ dewidawodsaraswati@gmail.com \\ Pendidikan Guru Sekolah Dasar \\ Fakultas Ilmu Pendidikan \\ Universitas PGRI Semarang
}

\begin{abstract}
Background of this research is that tematik teaching media are limited. It is influence the students interesting in learning process are not optimal. Statements of the problem of this research is how the development and analyze validation and practicability of tematik teaching media Magic Puzzle in teaching learning process theme kind of occupations in fourth grade in Primary School. Kind of this research is about Reasearch and Development with the procedure of ADDIE research. Population of this research is all students of Primary School 1 Nyamok are 30 students and all students of Primary School 2 Sumurjomblangbogo are 26 students in academic years of 2017/2018. This development results is tematik teaching media Magic Puzzle in theme of kind of occupation. The result of this study is validation from media expert and material expert with the ideal number of $90 \%$ and $80 \%$ and the perceptive of teacher and students with Magic Puzzle media with the ideal number of $83 \%$ and $97 \%$.
\end{abstract}

Key word: media development, magic puzzle media, theme of "berbagi pekerjaan"

\section{PENGEMBANGAN MEDIA PEMBELAJARAN TEMATIK MAGIC PUZZLE TEMA BERBAGAI PEKERJAAN KELAS IV SEKOLAH DASAR}

\begin{abstract}
Abstrak: Latar belakang yang mendorong penelitian ini adalah pengadaan media pembelajaran tematik yang masih terbatas sehingga kemaunan siswa dalam pembelajaran menjadi kurang optimal. Rumusan masalah dalam penelitian ini adalah bagaimana pengembangan media pembelajaran tematik Magic Puzzle yang valid dan praktis dalam pembelajaran tema Berbagai Pekerjaan kelas IV Sekolah Dasar. Jenis penelitian ini adalah Penelitian dan Pengembangan (Research and Development) dengan prosedur penelitian ADDIE. Populasi dalam penelitian ini adalah seluruh siswa SD Negeri 01 Nyamok yang berjumlah 30 siswa dan seluruh siswa SD Negeri 02 Sumurjomblangbogo yang berjumlah 26 siswa tahun pelajaran 2017/2018. Pengembangan menghasilkan media pembelajaran tematik Magic Puzzle tema berbagai pekerjaan. Hasil penelitian ini diperoleh melalui hasil validasi ahli media dan ahli materi dengan jumlah rata-rata keidealan yaitu $90 \%$ dan $80 \%$ serta hasil tanggapan guru dan siswa terhadap media Magic Puzzle dengan rata-rata keidealan $83 \%$ dan $97 \%$.

Kata kunci: pengembangan media, media magic puzzle, tema berbagai pekerjaan
\end{abstract}


Dewi \& Arfilia, Pengembangan Media Pembelajaran Tematik...

\section{PENDAHULUAN}

Pendidikan adalah usaha sadar dan terencana untuk mewujudkan suasana belajar dan proses pembelajaran agar peserta didik secara aktif mengembangkan potensi dirinya untuk memiliki kekuatan spriritual keagamaan, pengendalian diri, kepribadian, kecerdasan, akhlak mulia, serta keterampilan yang diperlukan dirinya, masyarakat, bangsa dan Negara. Hal tersebut termuat pada UU RI No. 20 Tahun 2003 tentang sistem pendidikan nasional pasal 1. Pendidikan dilaksanakan dalam suatu sistem pembelajaran.

Dalam pembelajaran harus diselenggarakan secara interaktif, menantang, memotivasi dan menyenangkan bagi peserta didik. Hal ini didasarkan pada Peraturan Pemerintah Republik Indonesia Nomor 19 Tahun 2005 tentang standar nasional pendidikan, pasal 19 ayat (1). Dalam hal ini, pembelajaran tak lepas dari media yang digunakan guna memotivasi peserta didik dalam proses belajar.

Menurut Djamarah (2013) kata "media" berasal dari bahasa latin dan merupakan bentuk jamak dari kata "medium", yang secara harfiah berarti "perantara atau pengantar". Media adalah wahana penyalur informasi belajar atau penyalur pesan. Media harus disesuiakan dengan isi dan tujuan pembelajaran yang telah dirumuskan. Media berperan penting dalam proses pembelajaran, karena melalui media guru dapat menyalurkan infomasi yang dibutuhkan oleh peserta didik. Selain berfungsi untuk menyalurkan informasi, media juga menjadi alat yang dapat memotivasi peserta didik dalam belajar. Dengan adanya media peserta didik akan lebih tertarik mengikuti pembelajaran karena terdapat sesuatu yang dapat diamati maupun dilakukan melalui pengadaan media. Berbeda halnya dengan pembelajaran yang tidak mengadakan suatu media, pembelajaran akan terasa membosankan dan bisa jadi hanya guru saja yang berperan aktif di dalam kelas tanpa adanya tanggapan dari peserta didik. Peserta didik hanya menjadi pendengar dan penerima informasi tanpa ada suatu kegiatan yang bermakna dalam proses pembelajaran.

Di era sekarang ini, pengunaan media sangatlah penting dalam proses pembelajaran. Penerapan kurikulum 2013 yang dirasa baru bagi sekolah-sekolah mendorong guru untuk lebih kreatif dalam membelajarkan peserta didik. Kurikulum 2013 merupakan pengembangan dari kurikulum sebelumnya untuk merespons berbagai tantangan-tantangan internal dan eksternal. Dalam proses pembelajaran peserta didik dituntut untuk berperan aktif bukan hanya sebagai penerima informasi saja. Media merupakan alat yang digunakan dalam proses pembelajaran untuk memberikan informasi yang dibutuhkan peserta didik. Namun penggunaan media yang ada saat ini masih terbilang terbatas.

Berdasarkan hasil observasi di lapangan yaitu pada SD Negeri 01 Nyamok dan SD Negeri 02 Sumurjomblangbogo Kabupaten Pekalongan, dari hasil wawancara dengan guru kelas IV serta hasil analisis kebutuhan sekolah mendapatkan hasil bahwa media yang digunakan di Sekolah Dasar tersebut masih bersifat sederhana saja. Sekolah belum mengadakan media pembelajaran tematik bagi peserta didik. Media-media yang 


\section{Dewi \& Arfilia, Pengembangan Media Pembelajaran Tematik...}

ada masih terbatas pada gambar dan benda konkret yang ada dilingkungan saja sehingga kurang menarik bagi peserta didik.

Dalam pembelajaran tematik itu sendiri, khususnya tema berbagai pekerjaan, guru hanya menggunakan media gambar dalam proses pembelajaran seperti gambargambar jenis pekerjaan dan untuk teks bacaan hanya terbatas teks yang ada dibuku. Sekolah belum mengembangkan dan menggunakan media khusus untuk pembelajaran tematik karena penerapan kurikulum 2013 yang masih baru sehingga belum tersedianya media yang memadai untuk membelajarkan pembelajaran tematik di kedua Sekolah Dasar tersebut.

Dengan pengadaan media yang belum optimal, mengakibatkan tingkat semangat dan kemauan belajar anak menjadi rendah, hal ini didasarkan dari hasil wawancara dengan siswa-siswikelas IV, siswa-siswi tersebut mengatakan bahwa apabila tidak ada media dalam pembelajaran dan media yang digunakan kurang menarik mengakibatkan semangat belajar rendah dibandingkan bila pembelajaran menggunakan media. Siswa kurang konsentrasi saat belajar karena media yang digunakan kurang menarik sehingga siswa kurang tertarik untuk memahami dan mengikuti pelajaran dan siswa mengalami kesulitan untuk memahami materi. Pada saat pembelajaran guru lebih sering menggunakan metode diskusi dan ceramah saja, jadi interaksi antara siswa dan guru masih kurang. Terkadang siswa masih sering berbicara dengan temannya dan tidak mendengarkan pada saat materi diajarkan, pada proses pembelajaran siswa masih bermain sendiri dan keadaan kelas tidak kondusif sehingga siswa tidak dapat mengikuti proses pembelajaran dengan baik. Jadi pada saat tanya jawab atau evaluasi berlangsung siswa masih kurang paham dan masih bertanya mengenai materi yang diajarkan.

Melihat dari karakteristik peserta didik sekolah dasar, pengadaan media sangatlah penting karena pada hakikatnya anak usia sekolah dasar masih bersifat bermain sambil belajar dan berpegang pada hal-hal yang konkret sehingga mudah dipahami anak. Kurangnya media dalam proses pembelajaran menjadikan anak malas dalam belajar sehingga pembelajaran yang berlangsung bersifat teacher center yaitu guru sebagai satu-satunya yang aktif padahal anak dapat menyerap materi ketika anak dilibatkan dalam kegiatan belajar dikelas. Pengadaan media dalam pembelajaran tematik yang masih baru perlu dilakukan karena dengan adanya media yang menarik dapat menghantarkan anak menyukai materi tanpa ada paksaan dan anak juga dapat lebih memahami daripada menghafal. Anak belajar tentang tanggungjawab ketika diberi kepercayaan untuk mengobservasi suatu kegiatan yang tujuannya untuk mendapatkan informasi suatu materi melalui media yang ada, seperti pada tema berbagai pekerjaan anak dapat mengobservasi berbagai jenis pekerjaan berdasarkan media bukan hanya mengarang tanpa adanya bantuan media. Dengan adanya media pendukung pembelajaran dan kreatifitas dari guru, siswa dapat merasakan bahwa sekolah adalah tempat belajar dan bermain yang indah. 


\section{Dewi \& Arfilia, Pengembangan Media Pembelajaran Tematik...}

Sehubungan dengan permasalahan di atas, peneliti berencana untuk mengembangkan media pembelajaran tematik tema berbagai pekerjaan sebagai media pembelajaran untuk menarik siswa dalam belajar. Media yang akan dikembangkan yaitu berupa media magic puzzle. Jamil (2012) mengemukakan bahwa puzzle merupakan bentuk teka-teki dengan model menyusun potongan-potongan gambar menjadi kesatuan gambar utuh. Dengan media puzzle dapat mengusik rasa ingin tahu anak sehingga mendorong anak untuk belajar. Disamping itu, guru juga akan mudah dalam menyampaikan pesan kepada anak, anak juga dapat bermain sambil belajar sehingga lebih memotivasi mereka dan anak akan lebih antusias untuk aktif belajar. Melihat dari karakteristik peserta didik sekolah dasar, pengadaan media sangatlah penting karena pada hakikatnya anak usia sekolah dasar masih bersifat bermain sambil belajar dan berpegang pada hal-hal yang konkret sehingga mudah dipahami anak. Kurangnya media dalam proses pembelajaran menjadikan anak malas dalam belajar sehingga pembelajaran yang berlangsung bersifat teacher center yaitu guru sebagai satu-satunya yang aktif padahal anak dapat menyerap materi ketika anak dilibatkan dalam kegiatan belajar di kelas. Pengadaan media dalam pembelajaran tematik yang masih baru perlu dilakukan karena dengan adanya media yang menarik dapat menghantarkan anak menyukai materi tanpa ada paksaan dan anak juga dapat lebih memahami daripada menghafal. Anak belajar tentang tanggungjawab ketika diberi kepercayaan untuk mengobservasi suatu kegiatan yang tujuannya untuk mendapatkan informasi suatu materi melalui media yang ada, seperti pada tema "berbagai pekerjaan", anak dapat mengobservasi berbagai jenis pekerjaan berdasarkan media bukan hanya mengarang tanpa adanya bantuan media. Dengan adanya media pendukung pembelajaran dan kreatifitas dari guru, siswa dapat merasakan bahwa sekolah adalah tempat belajar dan bermain yang indah.

Sehubungan dengan permasalahan di atas, peneliti berencana untuk mengembangkan media pembelajaran tematik tema berbagai pekerjaan sebagai media pembelajaran untuk menarik siswa dalam belajar. Media yang akan dikembangkan yaitu berupa media magic puzzle. Jamil (2012) mengemukakan bahwa puzzle merupakan bentuk teka-teki dengan model menyusun potongan-potongan gambar menjadi kesatuan gambar utuh. Disamping itu, guru juga akan mudah dalam menyampaikan pesan kepada anak, anak juga dapat bermain sambil belajar sehingga lebih memotivasi mereka dan anak akan lebih antusias untuk aktif belajar.

\section{METODE}

Metode penelitian yang digunakan dalam penelitian ini menggunakan metode penelitian pengembangan (R\&D). Menurut Sukmadinata (2016) "Penelitian dan pengembangan adalah suatu proses atau langkah-langkah untuk mengembangkan suatu produk baru atau menyempurnakan produk yang telah ada, yang dapat dipertanggungjawabkan". 
Dewi \& Arfilia, Pengembangan Media Pembelajaran Tematik...

Rancangan penelitian pengembangan yang digunakan mengacu pada model penelitian pengembangan (R\&D) ADDIE dalam Pribadi (2009). Model ADDIE terdiri dari lima tahap, yaitu: Analysis (analisis), Design (desain/merancang), Development (pengembangan), Implementation (penerapan), Evaluation (evaluasi).

Uji coba media dilakukan di dua sekolah dasar. Tempat dan waktu ujicoba media tersebut yaitu: SD Negeri 01 Nyamok pada kamis, 26 April 2018 dan SD Negeri 02 Sumurjomblangbogo pada jum'at, 27 April 2018. Subjek penelitian ini adalah seluruh siswa kelas IV SD Negeri 01 Nyamok dan siswa kelas IV SD Negeri 02 Sumurjomblangbogo. Jumlah siswa kelas IV di SD Negeri 01 Nyamok yaitu 30 siswa dan jumlah siswa kelas IV di SD Negeri 02 Sumurjomblangbogo yaitu 26 siswa.

Teknik pengumpulan data yang digunakan dalam penelitian pengembangan ini adalah teknik non tes dan dokumentasi. Teknik analisis data menggunakan dua teknik analisis data yaitu analisis deskriptif kualitatif dan analisis deskriptif kuantitatif. Data kualitatif berupa komentar dan saran perbaikan produk dari ahli media dan materi pembelajaran. Data kuantitatif berupa skor penilaian ahli media dan ahli materi serta serta pengisian lembar angket siswa terhadap media magic puzzle. Jenis skala yang akan digunakan oleh peneliti adalah skala Likert dan skala Guttman (Sugiono, 2016).

\section{HASIL}

Berdasarkan hasil penelitian di dua SD, media magic puzzle tema berbagai pekerjaan memiliki kriteria valid dan praktis untuk digunakan. Penilaian kevalidan dan kepraktisan dapat diketahui dengan rumus penilaian sebagai berikut:

$$
\text { Persentase }=\frac{\text { Jumlahskortotal }}{\text { Jumlahskormaksimal }} \times 100 \%
$$

(Sugiono, 2016)

Penilaian kevalidan dan kepraktisan media magic puzzle oleh ahli media, ahli materi, guru dan siswa diperoleh hasil sebagai berikut:

Tabel 1. Rata-Rata Persentase Keidealan Penilaian Ahli Media

\begin{tabular}{|c|c|c|c|}
\hline No & Ahli Media & Kriteria & Rata-rata Keidealan \\
\hline 1. & Dosen 1 & Layak & $80 \%$ \\
\hline 2. & Dosen 2 & Sangat Layak & $91 \%$ \\
\hline 3. & Dosen 3 & Sangat Layak & $99 \%$ \\
\hline
\end{tabular}

Tabel 2. Rata-Rata Persentase Keidealan Penilaian Ahli Materi

\begin{tabular}{|c|c|c|c|}
\hline No & Ahli Materi & Kriteria & Rata-rata Keidealan \\
\hline 1. & Dosen 1 & Layak & $74 \%$ \\
\hline 2. & Dosen 2 & Sangat Layak & $90 \%$ \\
\hline 3. & Guru 1 & Layak & $77 \%$ \\
\hline 4. & Guru 2 & Sangat Layak & $81 \%$ \\
\hline
\end{tabular}


Dewi \& Arfilia, Pengembangan Media Pembelajaran Tematik...

Tabel 3. Rata-Rata Persentase Keidealan Hasil Tanggapan Guru Kelas IV

\begin{tabular}{|c|c|c|c|}
\hline No & Perespon & Kriteria & Rata-rata \\
\hline $\mathbf{1 .}$ & Heni Subandiyah, S.Pd.,SD & Praktis & $77 \%$ \\
\hline $\mathbf{2 .}$ & Pujiastuti, S.Pd & Praktis & $89 \%$ \\
\hline
\end{tabular}

Tabel 4. Rata-Rata Persentase Keidealan Hasil Tanggapan Siswa Kelas IV

\begin{tabular}{|c|c|c|c|}
\hline No & Perespon & Kriteria & Rata-rata \\
\hline $\mathbf{1 .}$ & SD N 01 Nyamok & Sangat Praktis & $97 \%$ \\
\hline $\mathbf{2 .}$ & SD N 02 Sumurjomblangbogo & Sangat Praktis & $98 \%$ \\
& & & \\
\hline
\end{tabular}

\section{PEMBAHASAN}

Berdasarkan hasil penelitian di dua SD, media magic puzzle tema berbagai pekerjaan memiliki kriteria valid dan praktis untuk digunakan. Kevalidan media pembelajaran Magic Puzzle dapat dilihat dari persentase hasil uji ahli media dan ahli materi pembelajaran. Tabel 1 memaparkan penilaian yang dilakukan oleh ahli media dalam validasi media magic puzzle. Berdasarkan tabel rata-rata penilaian media pembelajaran tematik Magic Puzzle tema Berbagai Pekerjaan oleh semua ahli media diperoleh hasil yaitu sebesar $90 \%$ sehingga media pembelajaran tematik Magic Puzzle tema berbagai Pekerjaan termasuk dalam kriteria "Sangat Layak digunakan".

Pada tabel 2 memaparkan penilaian yang dilakukan oleh ahli materi dalam validasi media Magic Puzzle. Berdasarkan tabel 2 maka diperoleh hasil rata-rata penilaian media pembelajaran Magic Puzzle oleh semua ahli materi yaitu sebesar $80 \%$, sehingga berdasarkan penilaian ahli materi mengenai media pembelajaran tematik Magic Puzzle tema berbagai Pekerjaan termasuk dalam kriteria "Layak digunakan".

Tabel 3 dan 4 memaparkan hasil tanggapan guru dan siswa terhadap media Magic Puzzle yang juga dihitung rata-rata persentase keidealannya untuk mengetahui kepraktisan media Magic Puzzle. Tanggapan guru kelas IV sekolah dasar terhadap media pembelajaran Magic Puzzle yang dilakukan oleh Heni Subandiyah, S.Pd.,SD dari SD Negeri 01 Nyamok dan Pujiastuti, S.Pd dari SD Negeri 02 Sumurjomblangbogo, diperoleh rata-rata persentase keidealan dari penilaian keseluruhan indikator seperti yang terdapat pada tabel 3.

Berdasarkan rata-rata persentase keidealan hasil tanggapan setiap guru terhadap media pembelajaran Magic Puzzle pada keseluruhan indikator, maka diperoleh rata-rata persentase keidealan hasil tanggapan guru yaitu $83 \%$. Sehingga berdasarkan tanggapan guru mengenai media pembelajaran Magic Puzzle termasuk dalam kriteria praktis.

Tabel 4 memaparkan hasil tanggapan siswa kelas IV terhadap media pembelajaran Magic Puzzle oleh seluruh siswa kelas IV SD Negeri 01 Nyamok dengan 
Dewi \& Arfilia, Pengembangan Media Pembelajaran Tematik...

jumlah 30 siswa dan seluruh siswa SD Negeri 02 Sumurjomblangbogo dengan jumlah 26 siswa.

Berdasarkan rata-rata persentase hasil tanggapan siswa dari setiap sekolah terhadap media pembelajaran tematik Magic Puzzle pada tabel 4, maka diperoleh ratarata yaitu 97\%, sehingga berdasarkan tanggapan siswa melalui lembar angket media pembelajaran Magic Puzzle termasuk dalam kriteria "Sangat Praktis".

\section{SIMPULAN}

Media pembelajaran tematik Magic Puzzle Tema Berbagai Pekerjaan valid dan praktis digunakan dalam pembelajaran dengan rata-rata persentase keidealan kevalidan media dan materi yaitu $90 \%$ dan $80 \%$. Media pembelajaran tematik Magic Puzzle Tema Berbagai Pekerjaan praktis digunakan dalam pembelajaran dengan rata-rata persentase kepraktisan sebesar $83 \%$ dan $97 \%$.

\section{DAFTAR RUJUKAN}

Djamarah, S. B. \& Zain, A. 2013. Strategi Belajar Mengajar. Jakarta: PT Rineka Cipta. Hariyanto \& Suyono. 2016. Belajar dan Pembelajaran. Bandung: PT Remaja Rosdakarya.

Jamil, S. 2012. 56 Games Untuk Keluarga. Jakarta: Republika Penerbit.

Peraturan Menteri Pendidikan dan Kebudayaan Nomor 20 Tahun 2003 Tentang Sistem Pendidikan Nasional. 2003. Jakarta: Departemen Pendidikan Nasional.

Peraturan Menteri Pendidikan dan Kebudayaan Nomor 19 Tahun 2015 Tentang Standar Nasional Pendidikan. 2012. Jakarta: Departemen Pendidikan Nasional Pribadi, B. A. 2009. Model Desain Sistem Pembelajaran. Jakarta: PT Dian Rakyat. Sugiyono. 2015. Metode Penelitian Pendidikan. Bandung: Alfabeta. Bandung: Alfabeta. Sugiyono. 2016. Metode Penelitian Pendidikan. Bandung: Alfabeta. Bandung: Alfabeta. Sukmadinata, N. S. 2016. Metode Penelitian Pendidikan. Bandung: PT Remaja 